\title{
Are intentions reasons? And how should we cope with incommensurable values?
}

\author{
John Broome
}

\section{University of Oxford}

From: Practical Rationality and Preference: Essays for David Gauthier, edited by Christopher Morris and Arthur Ripstein, Cambridge University Press, 2001, pp. 98-120.

This paper has benefited from vigorous discussions at meetings in Copenhagen, Amsterdam and on the island of Raasay; I am very grateful to all those who were there. I particularly want to mention excellent written comments I received from David Donaldson, Joe Mintoff and Howard Sobel. Most of the paper was written while I was a Visiting Fellow at the Swedish Collegium for Advanced Study in the Social Sciences. I thank the Collegium for its very generous hospitality.

john.broome@philosophy.ox.ac.uk 


\section{Introduction}

If you intend to do something, does your intention constitute a reason for you to do that thing? To put the question briefly: are intentions reasons? Many philosophers have argued they are, but in this paper I shall argue they are not.

First thoughts are on my side. The view that intentions are reasons is implausible. If you have no reason to do something, it is implausible that you can give yourself a reason, just by forming the intention of doing it. How could you create a reason for yourself out of nothing? Suppose, say, that you have no reason either for against doing some act, and you happen to decide to do it. Now you intend to do it. So now, if intentions are reasons, you have a reason to do it. Since you have no contrary reason not to do it, the balance of reasons is in favour of your doing it. You now actually ought to do it, therefore. But this is implausible. It is implausible that just deciding to do something can make it the case that you ought to it, when previously that was not the case.

I shall call this 'the bootstrapping objection', in honour of Michael Bratman, who raises it in his Intentions, Plans and Practical Reason. ${ }^{1}$ The objection is that you cannot bootstrap a reason into existence from nowhere, just by a forming an intention.

Take an example. Suppose you are wondering whether to visit Paris, but have not yet made up your mind. There are reasons in favour and reasons against. Whether or not you ought to go depends on the balance of reasons. Now suppose you make up your mind to go, so now you intend to go to Paris. Ought you to go or not, now? What does that now depend on?

Before answering this question, I need to exclude some complicating factors. Your decision can create reasons in various indirect ways. Once it leads you to make some investment in going to Paris, reasons in favour of going there will begin to accumulate. If you have bought a non-refundable ticket, that adds to your reasons. Even if you have only got as far as calling the travel agent, that effort is still a small investment and may add to you reasons in favour of going. Some people value their resoluteness, and lose some of their selfesteem if they change their minds. For these people, every decision is automatically a sort of investment, and gives them a reason to carry it out. ${ }^{2}$ Reasons like this are the complicating factors that I need to exclude. They are consequences of your intention, but we are interested in whether the intention itself is a reason. To exclude these factors, let us suppose you have made no investment of any sort. You have simply decided to go to Paris, and so far done nothing about it. Also, you attach no particular value to resoluteness. Ought you to go or not?

The answer is intuitively clear. If the balance of antecedent reasons was in favour of your going to Paris, you ought to go there. You have made the right decision, and you ought to carry it out. If the balance of antecedent reasons was against your going to Paris, you ought not to go there. You have made the wrong decision and you ought not to carry it out. Even if the balance was only very weakly against going to Paris, still you should not go there, so long as you have not yet invested anything in getting there. Your intention itself does not count one whit in favour of going to Paris. It makes no difference to what you should do. What you should do depends only on the antecedent reasons.

Suppose there is a slight balance of antecedent reasons against going, but you made a mistake in your calculations and wrongly decided to go. A short time later, having invested nothing in the decision, you discover your mistake. Should you change your mind? If intentions were reasons, there would automatically be a reason not to, and if the balance of antecedent reasons was slight enough, you should stick to your decision. But actually you should surely change your mind. Since you have invested nothing in your wrong decision, you should change it. 
Intuitively, then, your intention of going to Paris is not itself a reason to go there. The slightest balance of genuine reasons against your intention means you should not carry it out.

This is an application of the bootstrapping objection. The example shows we can add a second objection as a corollary to the bootstrapping one: there is nothing in itself wrong with changing your mind. If you have an intention, there is nothing in itself wrong with giving it up. Certainly, there would be something wrong with it in some circumstances. For one thing, there may be a good antecedent reason why you should do the thing you intend to do. If so, it is likely also to be a reason for you to stick to your intention. For another thing, having formed the intention, you may have invested in it, and your investment may constitute a reason for sticking to it. But, apart from antecedent reasons and investments, there is no reason for you not to change your mind. I call this the 'objection from changing your mind'. It is a second objection to the view that intentions are reasons.

The bootstrapping objection and its corollary constitute a good prima facie case against this view. Many authors have offered contrary arguments, and one purpose of this paper is to answer those arguments. In view of the prima facie objections, I hope that will be enough to make the case that intentions are not reasons.

The paper has another purpose too. Intending to do something is not a reason to do it, but nevertheless a sort of normative relation does exist between intending and acting. I shall try to express accurately what this relation is. I hope that offering a better account of it will further reduce the attraction of the view that intentions are reasons.

Finally, I shall display this normative relation at work in a particular application. Some values are incommensurable with others. This incommensurability raises a problem for practical reason: how does a rational person act in the face of incommensurable values? I shall offer an answer, founded on my account of the normative relation between intending and acting.

\section{The pragmatic argument}

One argument for the claim that intentions are reasons is pragmatic. ${ }^{3}$ It has two steps. The first is to demonstrate that, if indeed intentions are reasons, our lives will go better than they would if they were not. The second is to argue from there to the conclusion that intentions are reasons.

I do not need to refute the pragmatic argument, since that has already been convincingly done by other authors. I have no quarrel with the first step; it is supported by many wellknown examples. But David Velleman, for one, has convincingly refuted the second step in his 'Deciding how to decide'. All I shall do here is add one more example in support of the first step. This example also demonstrates how implausible the second step is, so it ultimately works against the pragmatic argument.

One clarifying remark. The examples that support the first step of the argument only work if the reason created by an intention is a strong one - strong enough to defeat a significant contrary reason. A weak reason would not be enough; my example will show why not. So I slightly overstated the conclusion of the first step. The conclusion is that our lives will go better if intentions are strong reasons. Therefore, if the pragmatic argument succeeded in showing anything, it would show that intentions are strong reasons.

My example is a variation on - Gauthier might say a perversion of - one of David Gauthier's. Here it is.

You are leading your flock of sheep down from the mountain. In the last narrow defile before reaching the safety of the plain, you meet a wolf. If the wolf lunges into the flock, 
trying to grab a sheep, it will probably end up catching only a scrawny one. However, half the flock will die of fright or be lost over a cliff. Both you and the wolf know this, and you both know there is another course of action that would suit both of you better. It would be better for both if you handed over the juiciest of this year's lambs to the wolf, and in return the wolf allowed the rest of the flock to pass unmolested. Is there some way this desirable outcome could be achieved?

For the sake of argument, assume no contract can be made between you and the wolf, and no genuine promise issued, because no institutions of law or morality exist between the two of you. Assume the wolf is a migrant, and you will never meet it again. Assume both you and the wolf are rational, and this is known to both of you. Assume you are transparent to the extent that the wolf can accurately detect your intentions.

Now, suppose that intending something gives you a strong reason to do it (the degree of strength will appear in a moment). Then the desirable outcome could be achieved as follows. You could form the intention of presenting the best lamb to the wolf, if and when the rest of the flock has passed safely through the defile. We are supposing this intention gives you a reason to carry it out. Furthermore, the reason is strong - let us assume strong enough to outweigh the loss to you of the best lamb. Then, if the wolf allows the flock through the defile unmolested, the balance of your reasons will be in favour of your handing over the best lamb to the wolf. Since you are rational, you will do so. Moreover, the wolf will know all this. So it will know it can obtain the best lamb by letting the flock pass, whereas it will probably only get a scrawny sheep if it attacks. It will therefore not attack. Your flock will pass through, and you will hand over the lamb. The desirable outcome will be achieved.

On the other hand, if intending something is not a strong reason to do it, none of this will happen. Even if you manage to form the intention of handing over the best lamb to the wolf, the balance of reasons will be against your carrying out this intention, once the wolf has allowed the flock to pass. Being rational, you will not do so. The wolf will know this, so it will know it can gain nothing by letting the flock though. It will do best for itself by attacking and grabbing whatever sheep it can. You will lose half your flock.

In this example, therefore, both you and the wolf will do better if intentions are strong reasons. The same is true in many other examples. It seems reasonable to conclude in general that our lives would go better if intentions were strong reasons. Let us grant that. Should we then grant the second part of the pragmatic argument? Can we derive the conclusion that intending something actually is a strong reason to do it?

The example is very much against it. Suppose you successfully form the intention of handing over the best lamb to the wolf, and everything goes smoothly. The flock is safely through, and the time comes to sacrifice the lamb. Should you do so? Intuitively, it seems not. Nothing would be gained by your doing so. Your flock is safe; why should you give up a lamb? By doing so, you gain nothing and lose the lamb. You owe the wolf nothing, of course.

Gauthier evidently has the opposite intuition, but I suspect that is because he thinks of examples that are biased in the opposite direction. In his examples, carrying out your intention is generally a nice thing to do, independently of the intention. In my example, I deliberately made it a nasty thing to do. If it is not nasty enough to convince you, I can make it nastier. Let your flock be children, and the wolf a paedophile killer.

Still, this is only intuition, and the second step of the pragmatic argument needs a proper refutation. As I said, a convincing one is already available from Velleman, so I shall move on to other arguments. 


\section{The argument from instrumental reasoning}

Many authors have quite different grounds for thinking that intentions are reasons. They think that, if intentions were not reasons, they could not play the central role they do play in the management of our lives. Michael Bratman's Intention, Plans and Practical Reason is an excellent exploration of this role. I shall pick out some features of it.

First, if you intend to do something, your intention normally brings it about that you do it. This is the most fundamental way in which intentions help us manage our lives. By forming intentions, we gain some control over our future actions. Without this control, we could not carry out any concerted course of action that lasts some time. We would not have coherent lives.

When I say your intention 'brings it about' that you perform an action, I mean the intention causes the action. But the process is not merely causal. It is also a rational process; it involves reason. This is a second essential feature of the role that intentions play in our lives. They do not cause us to act mechanically, but through our reason.

To say the process involves reason is vague. There are, more precisely, at least two ways in which it does so. Each provides a distinct argument for the view that intentions are reasons. This section explains one way, and the next section the other.

The first way is that carrying out an intention often involves reasoning. Specifically, it involves instrumental reasoning. If you intend to achieve some end, then, commonly, by reasoning you will work out a suitable means of achieving this end, and form the intention of going about it by that means. By reasoning, we constantly derive intentions to take means from intentions to achieve ends.

It follows that our intentions must be able to figure as premises in our instrumental reasoning. It is sometimes argued that intentions could not perform this role unless they constituted reasons. This provides one argument for the view that intentions are reasons. I shall call it 'the argument from instrumental reasoning'.

It appears in Christine Korsgaard's paper 'The normativity of instrumental reasoning'. Korsgaard asks how the pursuit of an end requires you, rationally, to take a means to this end. How can you reason from intending an end to intending a means? Her answer is that the end must be invested with normativity. She thinks you cannot otherwise be rationally required to take the means. 'Unless there are normative principles directing us to the adoption of certain ends, there can be no requirement to take the means to our ends' ${ }^{4}$ Instrumental reasoning can transmit normativity from the end to the means, but it cannot itself give the means normativity.

However, Korsgaard is also opposed to the realist view that some ends have normativity in the nature of things - that it is in the nature of these ends that they should be pursued. So she thinks the normativity of an end must arise from the intention to achieve it. Just because you intend an end, that makes the end normative for you: you have a reason to achieve it.

Intending (willing) an end constitutes a reason to achieve it. Korsgaard says:

For the instrumental principle ['that practical reason requires us to take the means to our ends ${ }^{5}$ ] to provide you with a reason [to take the means to an end], you must think that the fact that you will an end is a reason for the end. It's not exactly that there has to be a further reason; it's just that you must take the act of your own will to be normative for you. And of course this cannot mean merely that you are going to pursue the end. It means that your willing the end gives it a normative status for you, that your willing the end in a sense makes it good. The instrumental principle can only be normative if we take ourselves to be capable of giving laws to ourselves - or, in Kant's own phrase, if we take our own wills to 
be legislative. ${ }^{6}$

\section{The argument from rationality}

The argument from instrumental reasoning derives from one of the ways in which reason is involved in the process that leads from intending to acting: instrumental reasoning often mediates the process. However, that does not always happen. Sometimes an intention causes an act more directly, without the intervention of instrumental reasoning. For instance, you may form the intention of patting your friend on the back, and do so, without reasoning about how to do so.

Nevertheless, even when the process that leads from intending to acting does not call on instrumental reasoning, it is still a rational process. It is part of our rationality that we usually carry out our intentions. (I say 'usually' because it is often rational to change ones mind, and not carry out an intention, as I said in section 1. I shall make the 'usually' more precise in section 7.) If we did not, usually, we would not be entirely rational. The process that leads from intending to acting is guided or controlled by reason, then. To put it another way, it is normatively sanctioned. This is a second way in which reason is involved in the process.

Some causal processes are rational processes. Reasoning is an example. In various ways, your existing intentions and beliefs cause you to acquire new intentions and beliefs. Some of these causal processes are normatively sanctioned as rational. Those ones constitute practical or theoretical reasoning. For instance, if one of your existing beliefs causes you (in the normal way and not by some deviant mechanism) to believe one of its logical consequences, that process is normatively sanctioned. It is a process of theoretical reasoning.

Not all normatively sanctioned processes are necessarily process of reasoning. If you believe you ought to do something, this belief will often cause you to do that thing. Moreover, the process whereby your belief causes you to act is normatively sanctioned, provided it occurs in a normal way. It ought to occur. If you do not do what you believe you ought to do, you are not fully as you ought to be. So this is a rational process. But we might not consider it a process of reasoning. Reasoning might bring you to believe you ought to do something, but we might not think it is reasoning that actually brings you to do it.

Similarly, the causal process that runs from intending something to doing it is a rational process, provided it occurs in the normal way. It may not be a process of reasoning, but that does not stop it from being a rational process.

Its rationality provides another argument for the view that intentions are reasons. The process that leads from intending something to doing it is a rational process. It is normatively sanctioned. But if this is so, it surely means that the intention gives you a reason to do the action. How else could it be a rational process? I shall call this 'the argument from rationality'.

In his 'Deciding how to decide', David Velleman first dismisses the pragmatic argument for the claim that intentions are reasons. I said that in section 2. He then goes on to offer a different argument of his own for the same conclusion. I think his argument is in effect the one I have just given.

True, he puts it differently. He stresses the autonomy of the process that runs from intending to acting, rather than its rationality. But in effect he identifies autonomous processes with rational ones. ${ }^{7}$ Undoubtedly, the process that runs from intending to acting is autonomous as well as rational. For one thing, you can turn it off: you can change your mind

and decide not to act after all. But for my purpose, it does not matter how the autonomy of the process is connected with its rationality. The argument that intentions are reasons must be 
founded on the process's rationality rather than its autonomy. Its premise must be that the process that runs from intending to acting is a rational one. Only from that premise does it apparently follow that intentions must be reasons. From the premise that the process is autonomous, that conclusion would follow only indirectly, at best.

\section{Normative requirements}

In order to answer the two arguments I presented in sections 3 and 4, I need first to examine rational processes in general. I shall use as an example the process of theoretical reasoning, because this one should be comparatively uncontroversial.

Suppose you believe some proposition $p$ from which $q$ can be inferred by an immediate valid inference. Then a rational process of theoretical reasoning will lead you from believing $p$ to believing $q$. But does it follow that believing $p$ is a reason to believe $q$ ? I shall argue that it does not.

From one point of view, this seems obvious. You might have no reason to believe $p$ in the first place. Indeed, it might even be the case that you ought not to believe $p$. Then obviously you may have no reason to believe $q$.

Moreover, this conclusion can be supported by a simple argument. The proposition $p$ itself follows from $p$ by an immediate valid inference. But your believing $p$ plainly cannot be a reason to believe $p$. Beliefs do not justify themselves; that would be an impossible sort of bootstrapping. So it cannot be a general principle that believing $p$ is a reason to believe $p$ 's immediate consequences.

Still, however obvious this may seem, there is a plausible contrary thought. If you believe $p$, then surely in some sense or other that is a reason to believe its consequence $q$, when $q$ is different from $p$ itself. No doubt, we would not say that believing $p$ is a reason to believe $p$ itself, because you do not need a reason for that; you already believe it. But if you are going to believe a consequence of $p$ that is distinct from $p$, you do need a reason for that, and surely believing $p$ is one, in some sense or other.

So two plausible views seem to conflict. But fortunately they can easily be reconciled. We may say that if you believe $p$, in some sense or other this is a reason to believe the consequence $q$, if $q$ is different from $p$ itself. Expressed more precisely, the position is that a particular relation holds between your believing $p$ and your believing $q$ : the first normatively requires the second, as I shall put it.

I have examined the notion of normative requirement more thoroughly in my paper 'Normative requirements'. Here I shall mention only its essential features. To say that believing $p$ normatively requires you to believe $q$ implies:

$$
\mathrm{O}(\mathrm{B} p \rightarrow \mathrm{B} q)
$$

where ' $O$ ' stands for 'you ought to see to it that', 'B' stands for 'you believe that', and ' $\rightarrow$ ' is the material conditional. (1) says you ought to see to it that, if you believe $p$, you believe $q$. But to say that believing $p$ normatively requires you to believe $q$ does not imply that, if you believe $p$, you have a reason to believe $q$ :

$\mathrm{B} p \rightarrow \mathrm{RB} q$,

where ' $R$ ' stands for 'you have a reason to'.

In (1) normativity is attached to the relation between believing $p$ and believing $q$, not to believing $q$ itself. On the other hand, (2) attaches normativity to the consequent rather than the relation. This means the consequent in (2) can be detached by modus ponens: from $\mathrm{B} p$ and (2), we can infer RBp. If you believe $p$, then (2) says you have a reason to believe $q$. A normative requirement does not allow detachment of that sort. We might say that, in a sense, 
believing $p$ is a reason to believe $q$, but the sense is misleading because, even if you believe $p$, you do not actually have a reason to believe $q$. From now on, I shall not use this misleading sense. The relation between believing $p$ and believing $q$ is not strictly that believing $p$ is a reason to believe $q$. It is that believing $p$ normatively requires you to believe $q$.

It is easy to confuse a reason and a normative requirement because they both involve a weakening of ought. A reason is a weakening of ought; it is an ought made pro tanto - an ought so far as it goes. If you have a reason to do something, and no reason not to do it, then you ought to do it. A normative requirement is also a weakening of ought; it is weakened by being made relative. It is easy to muddle the two types of weakening.

The difference between them can be described like this: a normative requirement is strict but relative; a reason is slack but absolute. A normative requirement is relative because it is a relation between two propositions. It is the truth of the first (such as your believing $p$ ) that requires you to see to the truth of the second (such as your believing $q$ ), and the requirement cannot be detached from its antecedent. But a normative requirement is strict because it is strictly a requirement: if you do not satisfy it, you have failed in something that is required of you. (1) expresses this strictness. It says you ought to see to it that if you believe $p$ you believe $q$. So if you believe $p$ but not $q$, you are definitely failing to see to something you ought to see to. On the other hand, a reason is not relative, but it is slack in that it is only pro tanto. If you do not do what you have a reason to do, you may not have failed in any way; you may have performed exactly as you should have. You may have had a better reason not to do this thing, and correctly followed the better reason.

The difference provides a useful test for distinguishing between a normative requirement and a reason. I call it 'the strictness test'. The relation between believing $p$ and believing $q$, when $q$ follows from $p$, is plainly strict. That is to say, if you believe $p$ and you do not believe $q$, you are definitely failing to see to something you ought to see to. If the relation was simply that believing $p$ was a reason to believe $q$, it would be slack; you might believe $p$ and not believe $q$, yet still be failing in no respect. This could happen if, say, you had a better reason not to believe $q$. But actually this is not possible. To be sure, you might have a good reason not to believe $q$, and an appropriate response might be to stop believing $p$. That way, you can escape from the requirement that is imposed on you by your belief in $p$. But if you do not take this way out, and you believe $p$ without believing $q$, you are not entirely as you ought to be. So the relation is strict, and it therefore cannot be that believing $p$ is a reason for believing $q$. It must be the relation of normative requirement.

This explains an important feature of theoretical reasoning. Suppose one of your beliefs is one you have no reason to have; indeed suppose you ought not to have it. Still, you can take it as a premise in your reasoning, and your reasoning will proceed exactly as it would in the more favourable circumstance where you ought to believe the premise. The nature of the reasoning is not affected by the merits of your belief in the premise. The reasoning that takes you from believing $p$ to believing $q$ is an example.

If reasoning had to give you a reason to believe the conclusion, this would not be possible. If you ought not to believe the premise, you may have no reason to believe the conclusion. But reasoning does not have to give you a reason to believe the conclusion. Instead, it reveals a normative requirement to believe the conclusion. Your belief in the premise may normatively require you to believe the conclusion, even if you ought not to believe this premise. For example, your belief in $p$ normatively requires you to believe $q$, even if you ought not to believe $p$. 


\section{Instrumental reasoning}

With the idea of a normative requirement in hand, I can return to the argument from instrumental reasoning. The argument is that we often reason on the basis of an intention to achieve some end, to arrive at an intention to take a means to that end. Evidently, therefore, this reasoning gives us a reason to take the means, and that would not be possible if we had no reason to achieve the end in the first place. So an intention to achieve the end must be a reason to do so.

Put briefly, the mistake in this argument is that instrumental reasoning does not give us a reason to take the means. Instead, intending an end normatively requires us to intend the means. Instrumental reasoning brings us to conform with this normative requirement: it brings us to intend the means to an end we intend. This is possible even if we have no reason either to achieve the end or to intend it.

To fill out this response to the argument, I need to examine the process of instrumental reasoning in more detail. My account is developed thoroughly in my 'Practical reasoning'. Here I shall be brief.

Here is an example of practical, instrumental reasoning

I am going to open the wine

and In order to open the wine, I must fetch the corkscrew,

so I shall fetch the corkscrew.

I mean (3a) to express an intention of yours, rather than a belief. I mean ( $3 b)$ to express a belief. I mean the conclusion (3c) also to express an intention.

You might actually go through this process of reasoning. Suppose you intend to open the wine, and then someone tells you the corkscrew is in the kitchen. This information imparts to you the belief that in order to open the wine, you must fetch the corkscrew. By reasoning, you form the intention of fetching the corkscrew.

Like all reasoning, this process takes you from existing states of mind to a new state of mind. It takes you from an intention and a belief to a new intention. To describe the process in more detail, I shall assume that your intentions and beliefs are propositional attitudes. That is to say, they are states of mind that have contents, and the contents are propositions. I shall assume your name is 'Pat', and I shall assume the proposition that Pat will open the wine is the same as the proposition that you, Pat, would express by saying 'I am going to open the wine'. So the content of your intention expressed in (3a) is the proposition that Pat will open the wine. Expressing propositions in the third person, we can describe your reasoning process explicitly as follows:

$\mathrm{I}($ Pat will open the wine)

and $\quad \mathrm{B}$ (In order for Pat to open the wine, Pat must fetch the corkscrew)

leads to I(Pat will fetch the corkscrew).

'B' stands for 'you believe that' and 'I' for 'you intend that'. (4) describes your reasoning. It is a description, not a derivation. If you intend to open the wine, and if you believe that in order to do so you must fetch the corkscrew, it does not follow that you intend to fetch the corkscrew. You might not have this intention if you are irrational, for instance.

On the other hand, (3) sets out the content of your reasoning. It has the form of a genuine derivation. Intuitively, it is valid reasoning; you are right to derive the intention of fetching the corkscrew from your existing intention and belief. Furthermore, it is indeed valid reasoning, as the following argument shows.

Start by comparing the practical reasoning described in (4) with this process of theoretical reasoning: 
B(Pat will open the wine)

and $\quad \mathrm{B}$ (In order for Pat to open the wine, Pat must fetch the corkscrew)

leads to $\mathrm{B}$ (Pat will fetch the corkscrew).

(To make it clear that this is theoretical reasoning concerned with beliefs, rather than practical reasoning concerned with intentions, imagine you are predicting your movements tomorrow, when you expect to be in a stupor.) Again, (5) is a description of reasoning rather than a derivation. Its content is:

Pat will open the wine

and In order for Pat to open the wine, Pat must fetch the corkscrew,

so Pat will fetch the corkscrew.

If you were running through this piece of reasoning, you would doubtless express it to yourself in the first person:

I shall open the wine

and In order for me to open the wine, I must fetch the corkscrew,

so I shall fetch the corkscrew.

Expressed in either the first or the third person, this content constitutes a valid inference. If its premises are true, the conclusion is true too. For this reason, the theoretical reasoning described in (5) is valid reasoning. It is valid because its content constitutes a valid derivation.

The content of the practical reasoning (4) is the same syllogism (6) as the content of theoretical reasoning (5). The difference between (4) and (5) is not in the propositions that constitute their content, but in the attitude you take towards these propositions. In the theoretical reasoning (5) your attitude is to take both premise as true. Because the conclusion is true if the premises are true, you cannot rationally take the premises as true without taking the conclusion as true. So your attitude towards the premises normatively requires you to take the conclusion as true. It requires you to believe it, that is. In the practical reasoning (4) your attitude towards the first premise is to set yourself to make it true. Your attitude towards the second premise is to take it as true. Because the conclusion is true if the premises are true, you cannot rationally set yourself to make the first premise true, and take the second as true, without setting yourself to make the conclusion true. Your attitude towards the premises normatively requires you to set yourself to make the conclusion true. It requires you to intend it, that is. ${ }^{8}$

Both (4) and (5) correctly track truth through the valid derivation (6). (5) tracks it in a truth-taking way, (4) in a truth-making way. Both therefore constitute valid reasoning. (5) is valid theoretical reasoning; (4) valid practical reasoning.

I shall use the term 'conclusion-state' for the mental state that results from a piece of reasoning, and the term 'premise-state' for a mental state from which reasoning sets out. If a piece of reasoning is valid, its conclusion-state is normatively required by its premise-states. So, in my example of practical reasoning:

I(I am going to open the wine)

and $\quad \mathrm{B}$ (In order to open the wine, I must fetch the corkscrew)

normatively requires $\quad \mathrm{I}(\mathrm{I}$ shall fetch the corkscrew).

The relation between premise-states and conclusion-states is not that the premise-states constitute a reason for the conclusion-state. You might be tempted to think that, in some sense or other, you have a reason to intend to fetch the corkscrew, if you intend to open the wine and believe that to do so you must fetch the corkscrew. But to see this is wrong, we can apply the strictness test that I mentioned in section 5. If you intend to open the wine, and 
believe that to do so you must fetch the corkscrew, you are definitely not entirely as you ought to be unless you intend to fetch the corkscrew. So the normative relation between premise-states and conclusion-state is strict, and therefore not the relation of being a reason for.

It is the relation of normative requirement. It does not allow a normative conclusion to be detached. Even if you intend to open the wine, and believe that to do so you must fetch the corkscrew, it does not follow that you have a reason to intend to fetch the corkscrew. Suppose, say, that you ought not to intend opening the wine in the first place, even though you do intend opening it. Then it may not be the case that you have a reason to fetch the corkscrew.

In general, intending an end normatively requires you to intend what you believe to be a necessary means to the end. It does not give you a reason to intend what you believe to be a necessary means.

This explains an important feature of instrumental reasoning. You can perfectly well reason from beliefs or intentions that you have no reason to have, and even that you ought not to have. Your reasoning proceeds in exactly the same manner whether or not this is so. If the result of the reasoning had to be that you have a reason for the conclusion-state, this would be inexplicable. Reasoning from beliefs and intentions you ought not to have could not give you a reason for the conclusion. But that is not how reasoning works. It works because the premise-states normatively require the conclusion-state.

This is the answer to the argument from instrumental reasoning. If you intend an end, you can take that intention as a premise in your instrumental reasoning, even if you have no reason to have this end. Intending the end need not give you a reason to pursue it; yet instrumental reasoning will still be possible.

\section{Intentions are normative requirements}

The idea of a normative requirement also provides the answer to the argument from rationality. The process that runs from intending an act to doing it is a rational process. The argument from rationality is that this could not be so unless the intention constituted a reason for the act. The answer is that a process does not have to provide a reason in order to be rational. Instead it may reveal a normative requirement. But I need to identify exactly what is normatively required by what.

Could it be that intending to do something normatively requires you to do it? To do the job it needs to do, this normative requirement would have to cross time. It would have to be that an intention you have at one time normatively requires you to act on it at a later time. An trans-temporal requirement is needed, because the central role of intentions is to control our future actions, as I said in section 3. The rational process that runs from intending an act to doing it is trans-temporal.

However, it is actually not the case that an intention you have at one time normatively requires you to act on it at a later time. That connection between intending and acting would be too strong. It would imply you ought to see to it that, if you intend to do something, you do it. So if you intend to do something at one time, but later change your mind and do not do it, you would not be entirely as you ought to be. That would mean you should not change your mind, once you had formed an intention. But I insisted in section 1 that there may be nothing wrong with changing your mind. So, whatever is the trans-temporal normative relation between intending and action, it must be weaker than this.

We can start to work out what it is by comparing another normative requirement, which is 
not trans-temporal. If you intend an end, that intention normatively requires you to intend what you believe to be a necessary means to the end. This requirement holds only between intentions that you have at one time, though I have not said so explicitly till now.

I described this requirement in section 6, and I said it does not imply that, if you intend the end, you have a reason to intend the means. Still less does it imply that you ought to intend the means. But if you do intend the end, and your intention normatively requires you to intend the means, how can it fail to imply that you ought to intend the means? Because it requires you to maintain consistency among your intentions, rather than to have a particular intention. There are two ways of maintaining this consistency: intend the means, or alternatively do not intend the end. If you decide not to take the means, that is fine: you only have to stop intending the end. Consequently, this normative requirement puts no obstruction in the way of your changing your mind.

But if an intention normatively required you to act on it in the trans-temporal way I described, there would be no second way of meeting the requirement, once the time of the original intention was past. At a later time, you cannot make it the case that you did not have the intention at an earlier time, so you can only meet the requirement by acting on it. That is why it goes too far to claim that an intention normatively requires you to act on it.

We can arrive at an appropriately weaker claim by introducing the idea of repudiating an intention. You cannot change a past intention, but you can repudiate it. I suggest it is permissible to change your mind, and not carry out one of your past intentions, but only provided you repudiate it.

I suggest that, if you intend to do something, and you do not repudiate this intention, your intention normatively requires you to do what you intend. In brief: unrepudiated intentions normatively require to be acted on. I think this correctly states the normative connection between intention and action. Repudiation supplies a second way out of the normative requirement, and so permits you to change your mind.

How do you repudiate an intention? Not simply by stopping having it, because that would reduce the requirement to no requirement at all. On the other hand, you do not necessarily need a reason to repudiate an intention. You may have acquired the intention for no reason, and consequently need no reason to give it up. I suggest repudiating an intention must at least be done deliberately; you must at least think about it for a moment. I suggest it also requires you to distance yourself from the intention - set yourself apart from it in some way.

One implication of my view is that if you simply forget one of your intentions, and fail to carry it out for that reason, that is a normative failure on your part. Over a short span of time, this is surely correct. If you intend to bring a loaf of bread home with you, but forget, then you have not performed entirely as you ought. But it has been suggested to me that there may be no normative failure if the forgetting takes a long time. Suppose that, as a child, you intend to visit Antarctica sometime in your life. But in due course you forget this intention, and you never visit Antarctica. Perhaps this constitutes no normative failing. If not, I shall need to qualify my claim that unrepudiated intentions require to be carried out. But in this paper I shall not try to work out precisely what the qualification needs to be. I shall deal only with fairly short time-spans, and ignore it.

I think mine is just the right account of the control that intentions give us over our lives. It accurately describes the degree of stability we gain from intentions, as rational people. As a causal matter, we usually carry out our intentions; once you have an intention, you usually retain it until you carry it out. Without this tendency, you would never be able to complete any course of action that takes time. Furthermore, the causal process that usually brings us to 
carry out our intentions is a rational one. It is normatively sanctioned. I can now say more precisely what this sanction amounts to: an intention normatively requires to be carried out, provided it is not repudiated. On the other hand, there may be nothing wrong with changing your mind and dropping one of your intentions. You have only to repudiate it.

How does this account compare with the rival view that intentions are reasons? The rival view can be similarly weakened to say that unrepudiated intentions are reasons: that $f$ you have an intention and do not repudiate it, it constitutes a reason to carry it out. This is certainly more plausible than the original unweakened view. It is no longer subject to the objection from changing your mind. It makes it permissible to change your mind, and drop an intention, provided you repudiate it. So the view that intentions are normative requirements has no advantage in this respect.

However, the bootstrapping objection still stands. The weakened version of the view that intentions are reasons says that, if you intend to do something, and do not repudiate your intention, it constitutes a reason to do it. This remains implausible. For instance, suppose you originally had no reason either for or against doing some act. For no reason, you formed the intention of doing it, and you have not subsequently repudiated your intention. Then this view says you now have a reason to do it. Since you have no contrary reason not to, you ought to do it. By merely intending to do it, you have made it the case that you ought to. This is implausible. Since we now have available the alternative view that intentions are normative requirements, we have no need to accept this implausible consequence.

To the bootstrapping argument, I can now add the strictness test. Is the relation between having an unrepudiated intention and acting on that intention strict or slack? Suppose you intend to do something, and you do not repudiate your intention, but you do not do what you intend. Have you definitely failed to act entirely as you should? Yes. To be sure, you might find you have a good reason not to do what you intend, so you ought not to do it. But in that case you should also repudiate your intention. Since your intention was to do something you ought not to do, you should repudiate it. If you do not, that is a normative failure on your part. This means the relation is strict. So by the strictness test, an unrepudiated intention constitutes a normative requirement rather than a reason.

\section{The practical problem of incommensurable values}

The rest of this paper illustrates this claim further through an example. I shall show how it successfully handles an important practical problem.

The problem is caused by incommensurable values. Sometimes we are faced with a choice where the alternatives realize such different values that it is impossible to weigh them against each other precisely. I shall call the values like this 'incommensurable'. When values are incommensurable, it may not be determinate which of the two alternatives is better. It may be that neither is better than the other, yet we also cannot say they equally good. When this happens, I shall say the alternatives are 'incommensurate'. I shall simply assume without argument that incommensurable values exist, and that we do sometimes encounter incommensurate alternatives.

Incommensurability can lead to a particular sort of practical difficulty. It appears most sharply if we assume teleology, and for the sake of argument I shall make this assumption. Teleology is the view that, when you have a choice among alternatives acts, which you ought to choose is determined only by the goodness of the alternatives. Nothing counts apart from goodness. There are no deontic constraints, for instance.

I shall take my example from Kierkegaard's Fear and Trembling. I do not mean to make 
any comment on Kierkegaard. I simply like the example.

God tells Abraham to take his son Isaac to the mountain, and there sacrifice him. Abraham has to decide whether or not to obey. Let us assume this is one of those choices where the alternatives are incommensurate. The option of obeying will show submission to God, but the option of disobeying will save Isaac's life. Submitting to God and saving the life of one's son are such different values that they cannot be weighed determinately against each other; that is the assumption. Neither option is better than the other, yet we also cannot say they are equally good.

Abraham has to decide. How should he do so? It is hard to know. Granted teleology, nothing apart from the goodness of the alternatives can contribute to determining what he should choose. But because the alternatives are incommensurate, their goodness does not determine that he ought to choose either one. It is not the case that he ought to obey God, and not the case that he ought not to. In circumstances like these, it is hard to know how a rational person should decide. This is one problem that incommensurability of value raises. But in this paper I shall not spend time on this problem, because it is not unique to incommensurability.

It also arises when a person has to choose between options that are equally good. In this case, too, it is not the case that she ought to choose one, nor that she ought to choose the other. How does a rational person choose in these circumstances? Buridan's ass, standing between two equally good bales of hay, demonstrated how difficult this question is. It was a highly rational creature, and so would choose only what it ought to choose. But neither bale was one it ought to choose, so it would not choose either. It died a martyr to its rationality. It would have been even more rational had it somehow managed to choose, even though neither bale was one it ought to choose. In cases of equal goodness and cases of incommensurateness, rationality certainly demands that one makes a choice. But how should one make it rationally? This difficult question is raised equally by cases of equal goodness and cases of incommensurateness. It is not a question for this paper. I shall simply assume the choice gets made somehow.

Somehow, Abraham makes his choice. Let us assume he decides to obey God, and sets out with Isaac for the mountain. However, as he travels, he can always change his mind. At any time, he can turn for home. For instance, he can turn back at the foot of the mountain. Having reached that point, he has the choice of turning back or carrying on to make the sacrifice. This is a choice he has to make.

If he turns back, Isaac will be safe, but the outcome will be decidedly worse than if he had never set out in the first place. By the time the two reach the mountain, Isaac is anxious about what is happening. He has seen his father bring the sacrificing knife, but no lamb for sacrifice. Trust between father and son is badly damaged. So turning back at the foot of the mountain is definitely worse than never setting out at all.

Let us assume nevertheless that turning back is incommensurate with carrying on to the make the sacrifice. This is possible. There can be three options $A, B$ and $C$ such that $A$ is definitely better than $B$, but both $A$ and $B$ are incommensurate with $C$. This possibility is characteristic of incommensurateness, and distinguishes it from equality of goodness: if $A$ is better than $B, A$ and $B$ cannot both be equally as good as a third option $C$. I do not need to dwell on this feature of incommensurateness in this paper, because it has been thoroughly analysed elsewhere. ${ }^{9}$

Let us assume Abraham's choices are an example. Staying at home $(A)$ is incommensurate with sacrificing Isaac $(C)$. Turning back at the foot of the mountain $(B)$ is also incommensurate with sacrificing Isaac, but turning back at the foot of the mountain is 
definitely worse than staying at home.

So, at the foot of the mountain, Abraham is faced with an incommensurate choice once again. Again it is difficult to know how he should make it. Let us imagine that at this point, somehow, Abraham decides to turn for home.

Abraham has now made two decisions. Both were between incommensurate alternatives. In neither case, therefore, was it determinate which option Abraham should choose. So neither of his choices was wrong: contrary to what he should have chosen. He seems to have done nothing irrational, therefore. Yet he has ended up taking a course of action that is decidedly worse than one he could have taken. He could have stayed at home. This would have been disobedient to God, but at least it would have kept intact his relationship with his son. As it is, Abraham has disobeyed God and also lost Isaac's trust.

Imagine Abraham had magically been presented, all at once, with an irrevocable choice among the three alternatives: stay at home $(A)$, set out to sacrifice Isaac but turn back at the foot of the mountain $(B)$, and set out and complete the sacrifice $(C)$. Then he definitely ought not to have chosen $B$, which is what he finally did choose. That would plainly have been irrational. Since the better alternative $A$ would have been available, he ought not to have chosen the worse one $B$.

Actually, Abraham's choices were not simultaneous, but separated by time. Yet still we might have hoped that rationality would have saved him from the bad result he fell into. Intuitively, his two decisions were in some way inconsistent with each other, and we might have hoped rationality would have saved him from that sort of inconsistency. Yet neither of his decisions was wrong. The reasons that were available to determine what he ought to choose - all stemming from the goodness of the options - left him free to settle both choices either way. They therefore did not constrain him tightly enough to save him from inconsistency. So it seems he did nothing irrational. His choices were apparently rational, even though they were intuitively inconsistent, and they led to a bad result.

This sets a puzzle. Were these choices really entirely rational? I think this is the distinctive problem that incommensurability raises, from a practical point of view. When values are incommensurable, it is apparently rational to make choices that are intuitively inconsistent with each other. Is it really rational $?^{10}$

\section{One solution}

One way of solving the puzzle is to say that our decisions make our values. When Abraham faced up to his first choice, neither option was better than the other, because the relevant values were incommensurable. But when he made his decision to sacrifice Isaac, he made it the case that for him this was the better thing to do. He made it the case that, for Abraham, sacrificing Isaac was better than disobeying God. The values as he first considered them obeying God and saving his son - left the alternatives incommensurate, but his choice made them commensurate for him. We might say that objectively they were incommensurate but subjectively, for Abraham once he had made his decision, the sacrifice was better.

On this view, making the sacrifice was better than staying at home, for Abraham. Therefore, it was certainly better than turning back at the foot of the mountain. So when Abraham faced his choice at the foot of the mountain, he ought to have stuck to his original decision. As it is, he chose the alternative that was worse, for him. This was irrational.

Rationality would indeed have saved him from the bad outcome, as we hoped it would. In this way, the puzzle would be resolved.

The idea that our decisions make our values is existentialist, but the rest of this story is not. 
Existentialists think our decisions make our values, but we must constantly remake them. The values we make for ourselves at one time do not determine what we should do at another time. ${ }^{11}$

This resolution of the puzzle is not existentialist, then, but it is an application of the view that intentions are reasons. Abraham's decision to sacrifice Isaac makes it the case that, for him, sacrificing Isaac is the best thing to do. His decision therefore gives him a reason to carry it out. Consequently, it gives him a reason not to turn back at the foot of the mountain. That is how the puzzle is resolved.

So the view that intentions are reasons, if it was correct, would provides a possible resolution of the problem of incommensurable values. But the bootstrapping objection remains. It is just not plausible that Abraham's decision can make it the case that he ought to sacrifice Isaac, when previously it was not the case. It is no more plausible under incommensurability than in any other circumstances. A decision simply does not add to preexisting reasons. We need a better resolution than this.

\section{A better solution}

When Abraham made his first decision, he formed the intention of sacrificing Isaac. I argued in section 7 that, so long as he does not repudiate this intention, it normatively requires him to carry it out. In the meantime, Abraham can use it as a premise in his practical reasoning. For example, at the foot of the mountain he can reason:

I am going to sacrifice Isaac,

and In order to sacrifice Isaac, I must climb the mountain,

so I shall climb the mountain.

This is instrumental reasoning in the pattern of section 6

It is a solution to the puzzle I posed in section 8 . There is, indeed, something in rationality that could have protected Abraham from the bad result of turning back at the foot of the mountain. The intention formed in his first decision normatively required him not to turn back. Neither of Abraham's choices was contrary to what he ought to have done, but the second choice was contrary to a normative requirement imposed on him by the first choice. So he did indeed act irrationally.

I said his choices were intuitively inconsistent in some way. Simply avoiding acting wrongly - contrary to what he ought to do - was not enough to make them intuitively consistent, because what he ought to do was too indeterminate. But if he followed the normative requirement he was under, he would have made intuitively consistent choices. The inconsistency that we identified intuitively now turns out to be a failure to satisfy a normative requirement.

However, all of this depends on Abraham's not repudiating the intention he formed in his first decision. He has no reason not to repudiate it, because he had no reason to form this particular intention in the first place. And by repudiating it he can release himself from the requirement it imposes on him. Provided he repudiates this intention, there is indeed nothing irrational about his turning back.

So the solution I have offered to the puzzle of incommensurability is extremely fragile. Rationality can save Abraham from the bad outcome, but only by the slenderest of threads. He only has to repudiate his intention, and the bad outcome can result without any irrationality on his part.

I think this fragile solution of the puzzle is the right one. It is the best that can be had. I do not think rationality could, in any more robust fashion, have saved Abraham from the 
unfortunate outcome of turning back at the foot of the mountain. Even if Abraham was entirely rational, he could have ended up with that result.

True, if he had been presented with all three alternatives at once, rationality would definitely have saved him from this bad outcome, as I explained in section 8. Even then, he would not necessarily have ended up with a better outcome. He might have sacrificed Isaac, and our assumption is that that is not better than turning back at the foot of the mountain; these two alternatives are incommensurate. In any case, the fact that the decision-making was actually spread over time makes a genuine difference to the situation, so we must expect that the outcome might rationally be different.

Abraham was actually not presented with all three alternatives at once. He had an opportunity to think again about his first decision, as he rode towards the mountain. He might not have taken this opportunity. In that case, if he was rational, he would have carried on to make the sacrifice. His original decision would have remained unrepudiated, and the final result would not have been the bad one of turning back. In this case, rationality in the form of a normative requirement would have maintained consistency between Abraham's decisions.

But if Abraham did think again, there was nothing irrational in his doing so. His original decision was not made for reasons, so he was entitled to rethink it. Indeed, since he was riding to sacrifice his son, it would perhaps have been pigheaded of him not to. Moreover, if Abraham thought again, and the result of his rethinking was that he repudiated his original intention, there was nothing irrational in that either. It need not be irrational to be irresolute.

It he repudiated his decision, it was a change of heart and mind. It is an unfortunate fact about changing your mind that you often have to make the best of a bad job. You have to bear the cost of the decision you have now turned away from. Having repudiated the decision to sacrifice Isaac, Abraham should then have been pleased he had the chance to pull back. The final result was not ideal, but it was the best of a bad job.

In sum, to be rational, Abraham must not turn back without rethinking his decision. But if he does rethink it, and deliberately repudiates it, he may rationally turn back.

Notes

1. pp. 24-7.

2. I owe this point to Howard Sobel.

3. Two proponents of the pragmatic argument are David Gauthier, in Morals by Agreement and 'Assure and threaten', and Edward McClennen, in Rationality and Dynamic Choice.

4. Korsgaard, 'The normativity of instrumental reason', p. 220.

5. This definition of the instrumental principle is implicit on p. 215.

6. pp. 245-6.

7.p. 45.

8. I am oversimplifying when I identify intending with the attitude of being set to make true.

Not all cases of being set to make true are cases of intending. So here I am skating over some complications. Details are in my 'Practical reasoning'.

9. For example in Joseph Raz's 'Value incommensurability'. In my 'Incommensurable values', I argue that this is actually the defining feature of incommensurateness, which distinguishes it from equality. Raz describes this same characteristic feature of incommensurateness, but denies it is the defining feature.

10. My 'Incommensurable values' sets out the puzzle in more detail. Ruth Chang raises the same puzzle in her introduction to Incommensurability, Incomparability and Practical Reason, p. 11. 
11. Thanks to Philippe Mongin for this point.

\section{References}

Bratman, Michael E., Intention, Plans and Practical Reason, Harvard University Press, 1987. Broome, John, 'Incommensurable values', in Well-Being and Morality: Essays in Honour of James Griffin, edited by Roger Crisp and Brad Hooker, Oxford University Press, 1999.

Broome, John, 'Normative requirements', Ratio, 12 (1999), pp. 398-419.

Broome, John, 'Practical reasoning', typescript.

Chang, Ruth, 'Introduction', in Incommensurability, Incomparability and Practical Reason, edited by Ruth Chang, Harvard University Press, 1998, pp. 1-34.

Gauthier, David, 'Assure and threaten', Ethics, 104 (1994), pp. 690-721.

Gauthier, David, Morals by Agreement, Oxford University Press, 1985.

Korsgaard, Christine, 'The normativity of instrumental reason', in Ethics and Practical Reason, edited by Garrett Cullity and Berys Gaut, Oxford University Press, 1997, pp. 215-54.

McClennen, Edward F., Rationality and Dynamic Choice, Cambridge University Press, 1990. Raz, Joseph, 'Value incommensurability: some preliminaries', Proceedings of the Aristotelian Society, 86 (1985-86), pp.117-34.

Velleman, David, 'Deciding how to decide', in Ethics and Practical Reason, edited by Garrett Cullity and Berys Gaut, Oxford University Press, 1997, pp. 29-52. 